\title{
El pabellón español de los hexágonos o el sueño de una noche de verano
}

\author{
$\mathrm{M}^{\mathrm{a}}$ Ángeles Cejador Ambroja
}

${ }^{a}$ Universidad de Zaragoza, C/ Pedro Cerbuna 12, 50001, Zaragoza. mangelesceam@gmail.com

\begin{abstract}
Resumen
Concluida la Segunda Guerra Mundial volvieron a celebrarse Exposiciones Internacionales, eventos que fueron clave para cambiar la imagen de los países que en ellas participaban. España comenzaba a resurgir y se encontraba ansiosa por conseguir aproximarse a las naciones democráticas, por lo que la participación en la Exposición Universal de Bruselas de 1958 supuso la oportunidad de dejar a un lado, a través de la arquitectura, su polémico pasado ante el resto del mundo. Para conseguir ese objetivo eligió el pabellón proyectado por los arquitectos José Antonio Corrales y Ramón Vázquez Molezún. Fue considerado un hito histórico, pero ¿qué sucedió tras finalizar la Exposición Universal?

Terminado el evento, el pabellón se trasladó al Recinto de la Casa de Campo en Madrid en 1959 y permaneció abierto hasta 1975. En varias ocasiones, estuvo a punto de cambiar su destino y mientras, la maleza junto con la desidia, se fueron apropiando de esta construcción. Su historia es el símbolo del desafortunado sino al que se han visto sometidos algunos singulares ejemplos españoles de la arquitectura del siglo XX. El análisis de la fortuna historiográfica y social de este pabellón puede servir para reflexionar cómo conservar mejor la arquitectura contemporánea.
\end{abstract}

Palabras clave: Expo Bruselas 1958, pabellón de España, arte, franquismo, arquitectura contemporánea, José Antonio Corrales, Ramón Vázquez Molezún.

\footnotetext{
Abstract

At the end of World War II, International Exhibitions were held again, events that were key to changing the image of the countries that participated in them. Spain that was beginning to re-emerge and was eager to get approaching democratic nations, found in participation in the 1958 Brussels World's Fair the opportunity to set aside, through architecture, his controversial past to the rest of the world. To achieve this goal, the pavilion designed by the architects José Antonio Corrales and Ramón Vázquez Molezún was chosen. It was considered a historical landmark but, what happened after the end of the Universal Exhibition?

After the event was completed, the pavilion moved to the Casa de Campo in Madrid in 1959 and remained open until 1975. On several occasions they nearly changed their fate and, in the meantime, the undergrowth along with the sloth, became the appropriation of this construction. Its history is the symbol of the unfortunate destiny to which have been subjected some unique Spanish examples of 20th century architecture. The analysis of the historiographic and social fortune of this pavilion can serve to reflect on how to best preserve contemporary architecture.
}

Keywords: Brussels Expo 1958, Spain Pavilion, art, francoism, José Antonio Corrales, Ramón Vázquez Molezún. 


\section{Contexto histórico y cultural: los años cincuenta del siglo pasado}

Las Exposiciones Internacionales celebradas a lo largo de los dos últimos siglos se pueden considerar como pasarelas de desfile de tendencias y punto de referencia para la historia de la arquitectura. El objetivo de todas ellas siempre ha sido mostrar una imagen del país, estimular los intercambios culturales a través de lo expuesto en el interior de los pabellones y conseguir situarse en un lugar destacado dentro del ámbito internacional.

Concluida la Segunda Guerra Mundial y tras casi veinte años sin celebrarse certámenes internacionales, la Exposición Universal de Bruselas de 1958 tuvo un papel relevante en la historia de estas muestras. Se trató del mayor foco cultural desde el comienzo de la Guerra Fría, lo que supuso una ocasión para que muchos países de ambos bloques aprovecharan para exhibir sus logros o mejorar su imagen internacional. Este certamen ayudó a familiarizar al gran público con la arquitectura moderna, reflejando la variedad que mostraba la arquitectura de posguerra, que sirvió para crear una imagen de nación desarrollada y transmitir a los miles de visitantes los éxitos conseguidos tras la desgracia de la guerra.

Al comienzo de la década, en el campo de la arquitectura española comenzó a manifestarse la voluntad de repensar las directrices arquitectónicas de corte neo-imperial que las instancias oficiales habían establecido. Por un lado, se buscaba enlazar la experiencia, truncada por la guerra, de la arquitectura racionalista, impulsada en los años treinta por muchos arquitectos tanto de forma individual como colectiva por el GATEPAC. Por otro lado, el interés se dirigía al panorama contemporáneo en otros países de Europa, en los que desde los años treinta la arquitectura moderna había experimentado diversas evoluciones (Cortés, 2000).

En los años cincuenta comenzaba en España la aventura de una sobresaliente generación de arquitectos que aligeraba el paso para desarrollar la modernidad que le había sido negada. Dieron lugar a estilos diversos, puesto que encontramos importantes e interesantes obras de arquitectos como Coderch y Fisac, representantes de un revisionismo arquitectónico que ponía en duda algunos aspectos de la continuidad del racionalismo originario, mientras que al mismo tiempo también dejaron su huella las obras de arquitectos como García de Paredes, La Hoz, Sostres, Corrales, Vázquez Molezún y De la Sota, entre otros, que apostaron por dicha continuidad, pero propusieron versiones muy diversas entre sí (Cortés, 2000).

Fue en este contexto cuando la participación española en la Exposición Universal celebrada en Bruselas en 1958 supuso un antes y un después para la nación. Los esfuerzos realizados para asistir a este evento se vieron recompensados con el gran éxito reportado por el Pabellón de España que los arquitectos José Antonio Corrales y Ramón Vázquez Molezún proyectaron para la ocasión. Esta obra ganó el Primer Premio en la Exposición y fue considerado uno de los mejores edificios de la arquitectura española del siglo XX. Pero veremos cómo a pesar de haber sido estimado como un hito histórico que marcó el momento en el que la arquitectura moderna se convirtió en el estilo oficial y dejaba relegada a la arquitectura de corte historicista que se había mantenido hasta el momento, su estado actual no refleja la situación gloriosa, aunque efímera, que vivió (Baldellou y Capitel, 1996).

\section{El proyecto ganador}

El pabellón español en la Exposición Universal de Bruselas ha sido considerado históricamente por los críticos nacionales e internacionales como el más significativo por ser elegido para representar a la España de aquel tiempo ante Europa y el mundo, intentando terminar con la imagen de aislamiento. Esta construcción se abordó mediante un concurso de ideas planteado por el Ministerio de Asuntos Exteriores en marzo de $1956^{1}$. En este se pedía una propuesta de pabellón que fuera desmontable puesto que el objetivo era que, cuando terminara el certamen, se pudiera recuperar la mayor cantidad de materiales para compensar el desembolso económico realizado para su levantamiento (hecho comprensible en un país que todavía se encontraba en una débil situación financiera). Las proposiciones del concurso pedían también que el proyecto fuera flexible ya que se tenía que adaptar al terreno de una colina, con un contorno irregular y un frondoso arbolado que había que respetar (Jerez, 2012).

\footnotetext{
${ }^{1}$ Revista Nacional de Arquitectura, n.175, Julio 1956, p. 13.
} 
De entre todas las propuestas, la elegida fue la presentada por José Antonio Corrales y Ramón Vázquez Molezún, porque fue considerada por el jurado como la que mejor había interpretado las bases del concurso con un proyecto de extraordinaria calidad. (Fig. 1). En palabras del arquitecto Miguel Fisac, autor del informe realizado por la comisión, "tenía una espacialidad, un tratamiento de la iluminación y una organización estructural y constructiva rigurosamente moderna y enraizada, a la vez, en la mejor tradición española”.

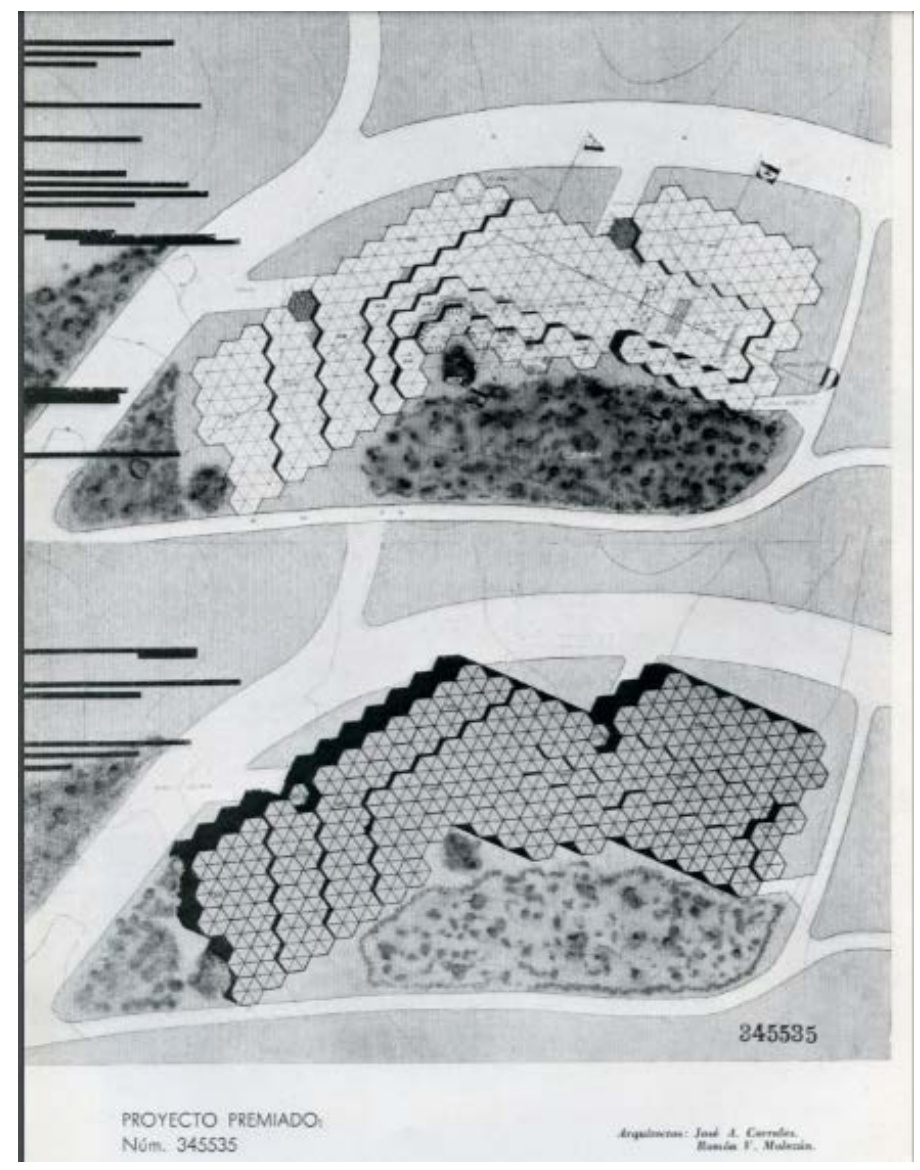

Fuente: Revista Nacional de Arquitectura, n.175 (1956)

Fig. 1 Proyecto premiado del pabellón español

La obra que dio a Corrales y Molezún nombre fuera de nuestras fronteras estaba constituida por una estructura de paraguas hexagonales, capaz de acoplarse a cualquier terreno, como así lo hizo en el Parque Heysel de Bruselas donde se extendió, sorteando las irregularidades del terreno, incorporando a los árboles del lugar y consiguiendo un movimiento y una iluminación de gran flexibilidad (Ruiz, 2001). El pabellón presentaba formalmente un corte organicista y se realizó con aluminio, ladrillo y cristal, entre otros materiales. Su interior recordaba, según algunos críticos, a la sala hipóstila de la mezquita de Córdoba por la repetición de columnas que, en el caso del pabellón, le daban un aspecto fluido a un espacio que tenía distintos niveles, entradas de luz natural y ambientes diferenciados mediante escaleras, rampas y cerramientos opacos que se alternaban con paños de vidrio (Fernández, 2011) (Fig. 2).

El sistema que Corrales y Molezún diseñaron había sido ideado como un mecano que se podía desmontar y trasladar sin demasiadas complicaciones, dotando a la estructura de flexibilidad y libertad. Gracias a esto el pabellón pudo ser transportado sin problemas desde Bruselas hasta la Casa de Campo de Madrid, lugar en el que actualmente se encuentra en un lamentable e increíble estado de ruina debido a que desde 1975 no ha recibido un uso concreto que devolviera la valía que tiene y merece ser reconocida. 


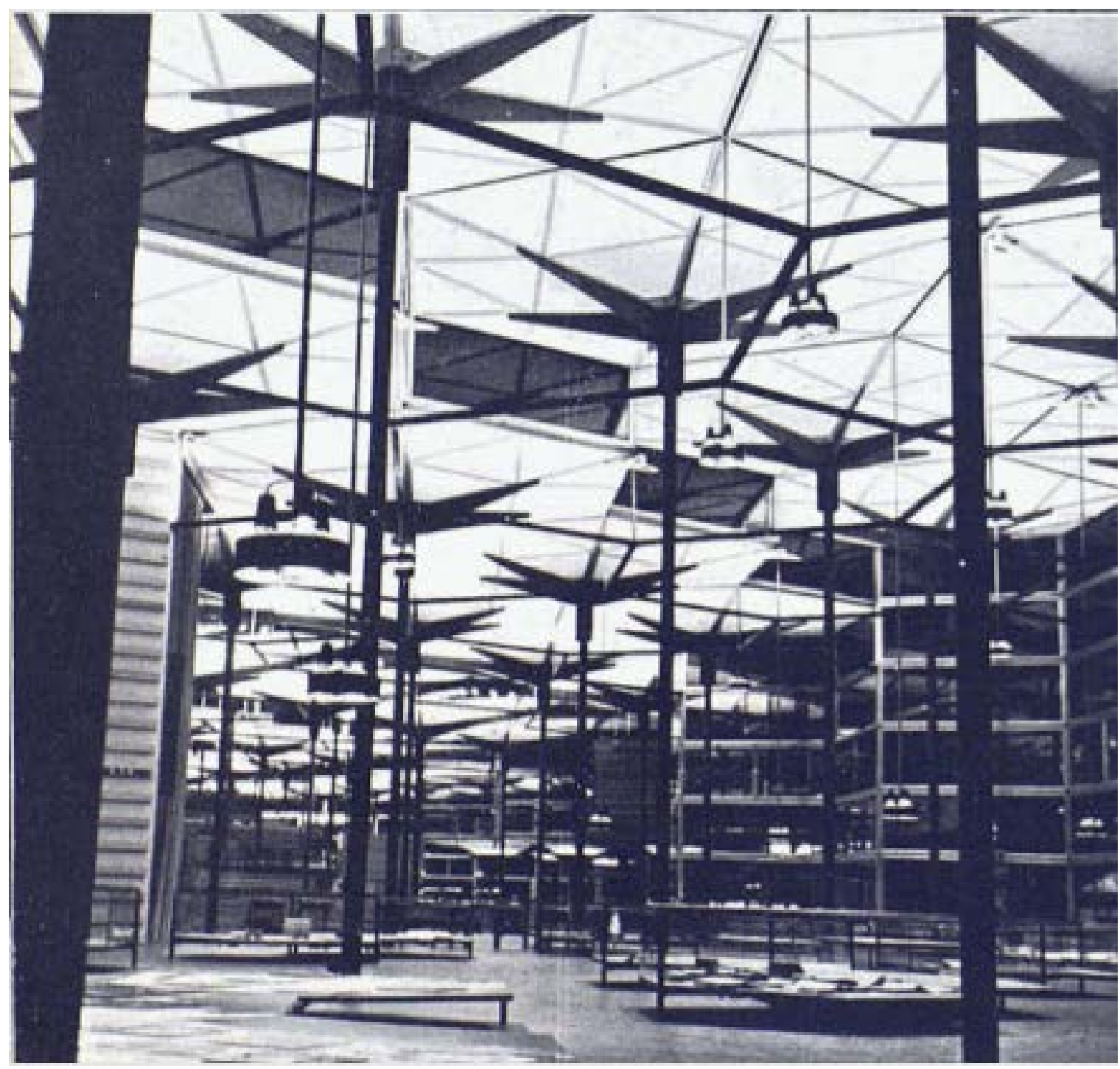

Fuente: Revista Cuadernos de Arquitectura, n.32 (1958)

Fig. 2 Vista del interior

\section{La fortuna crítica del pabellón}

El inesperado impacto que causó el Pabellón de España fue evidente como muestra el considerable número de artículos que se publicaron en las revistas especializadas de la época, tanto nacionales como internacionales. Como hemos comentado anteriormente, la célebre Revista Nacional de Arquitectura publicó en 1956 el fallo del concurso y adjuntó los paneles de las ocho propuestas que se presentaron; al año siguiente, en 1957, publicó otro artículo sobre el pabellón español en el que daban más detalles del proceso constructivo del edificio e informaban de la adjudicación de la instalación interior a Corrales y Molezún ${ }^{2}$. En otras revistas de ámbito nacional como Cuadernos de Arquitectura ${ }^{3}$ o Informes de la Construcción ${ }^{4}$, y en las extranjeras Casabella ${ }^{5}$, The Architectural Review ${ }^{6}$ o L'Architecture

\footnotetext{
2 "Exposición Universal e Internacional de Bruselas, 1958", Revista Nacional de Arquitectura, n.188, agosto 1957, p. 5.

3 "Expo 1958: Bruselas", Cuadernos de Arquitectura, n. 32, 1958, pp. 36-40.

4 “Bruselas-Expo,1958. Pabellón de España”, Informes de Construcción, n. 106, diciembre 1958, pp. 1-10 (de la versión digitalizada por el Consejo Superior de Investigaciones Científicas).

5 "El Pabellón de España: Bruselas “, Casabella, n.221, noviembre 1958, pp. 16-17.

6 “The Brussels Exhibition”, The Architectural Review, n.739, August 1958.
} 
d`Aujourd 'hui ${ }^{7}$ elogiaron la delicada y sobria belleza, así como la armonía e ingenio en las formas de un pabellón que llegó a ser una obra única para su tiempo, especialmente en el ámbito internacional ${ }^{8}$.

Por lo tanto, vemos como la obra de Corrales y Molezún sirvió para llamar la atención de los arquitectos extranjeros asombrados por la moderna arquitectura que presentaba España y que chocaba con la que, por los mismos años se estaba realizando en el interior del país. Es probable que esa "contradicción formal" entre la imagen exterior proyectada por el régimen franquista en 1958 y la intramuros, fuera lo que suscitara curiosidad entre los arquitectos y críticos internacionales (Hernández, 2013).

Periódicos como el diario $A B C$ publicaron numerosas noticias al respecto ${ }^{9}$, así como una entrevista del que fue el primer comisario del pabellón español, el Marqués de Santa Cruz, en la que este expresaba las pretensiones de España con la participación en la Exposición Universal ${ }^{10}$. En el diario La Vanguardia Española también encontramos un buen número de artículos en los que se narraban primicias de la inauguración de la Exposición Universal y del tan ansiado pabellón español cuya apertura se retrasó ${ }^{11}$. De seguro resultarían también interesantes para el público de la época las noticias que trataban sobre las distintas actividades que tendrían lugar durante la muestra en nuestro pabellón ${ }^{12}$ o los galardones recibidos como reconocimiento a la magnífica arquitectura e instalación interior del edificio español que tanto éxito produjo ${ }^{13}$.

Las revistas nacionales de la época dedicaron asimismo artículos de sus páginas, como la famosa Blanco y Negro, en cuyo artículo "Presencia del cine en la «Expo 58» de Bruselas"14 analizaba los distintos pabellones de la Exposición, aludiendo a los que a su parecer resultaban más interesantes. La labor de difusión de la fama que estaba teniendo el pabellón español entre el público visitante no podía olvidarse, como es lógico, de ser transmitido a través del noticiario y los documentales cinematográficos $N O-D O$ que durante el régimen franquista y hasta 1981 se proyectaban en los cines españoles antes de cada película ${ }^{15}$. En enero de 1958 la revista cinematográfica Imágenes ${ }^{16}$ presentaba interesantes escenas del Pabellón de España, así como de los contenidos que en él se estaban exponiendo y los diferentes eventos que se celebraban en su interior.

La modernidad y el atractivo de esta obra made in Spain estuvo en el punto de mira de todos los medios de comunicación contemporáneos a la emblemática Exposición Universal de Bruselas -no era para menos-, puesto que España había conseguido "romper esquemas" con su manera de presentarse ante el mundo. El objetivo del régimen de lavado de imagen en el exterior parecía haberse cumplido, a pesar de las idas y venidas acaecidas con el proyecto de su instalación interior (Cejador, 2019).

\footnotetext{
7 "Bruselas 1958. Exposición Universal e Internacional”, L'Architecture d'Aujourd'hui, n.76, 1958, pp. 96-100.

${ }^{8}$ La revista francesa "L'Architecture d'Aujourd'hui" en su artículo "Pavillon de l'Espagne" del número 78 decía: "La cuestión no ha estado aquí en mostrar, como en el pabellón de Francia, la mayor cantidad posible de objetos, sino, al contrario, en sugerir a través de las fotografias, de la música y los bailes, el ambiente y el espíritu de un país", junio 1958, p. 21.

9 “España en la próxima Exposición de Bruselas", $A B C$, (Madrid, 7-I-1956), p. 28. "La Exposición Universal de Bruselas”, $A B C$, (Madrid, 28-II1957), p. 9. "España acudirá a la Exposición Universal de Bruselas de 1958”, $A B C$, (Madrid, 27-VII-1957), p. 42, entre otras noticias.

10 "La Exposición Universal de Bruselas de 1958 será la primera que se realizará después de la última conflagración mundial", $A B C$, (Madrid, 28-VII1957), p. 23.

11 “Apertura al público del pabellón de España en Bruselas”, La Vanguardia Española, (Barcelona, 8-V-1958), p. 38.

12 “Actividades en el Pabellón español de la «Expo»”, La Vanguardia Española, (Barcelona, 6-VIII-1958), p. 9.

"No todo es técnica en la Exposición. El pabellón de España y el baile de la Corte”, La Vanguardia Española, (Barcelona,18-IV-1958), p. 17.

13 "El gran éxito del pabellón español en la «Expo»”, La Vanguardia Española, (Barcelona, 7-IX-1958), p. 11.

"Distinción al pabellón español de la «Expo»”, La Vanguardia Española, (Barcelona, 22-X-1958), página de portada.

14 "Presencia del cine en la «Expo 58» de Bruselas", $A B C$, (Madrid, 15-XI-1958), pp. 75-77.

${ }^{15} \mathrm{~A}$ lo largo de los meses que duró la Exposición Universal, en algunos documentales del NO-DO aparecieron noticias sobre el éxito del pabellón español. (Cfr. NO-DO, Archivo Histórico, No 800A, 05-V-1958; № 801A, 12-V-1958; № 812B, 28-VII-1958; № 825B, 27-X-1958).

${ }^{16}$ NO-DO, Revista Imágenes, № 709, 1-I-1958.
} 


\section{Un nuevo "hogar" para el pabellón}

Terminada la Exposición muchos de los pabellones se desmontaron y trasladaron a sus países de origen para pasar a mejor o, dependiendo de la nación, a peor vida. En el caso de España, tras pensar en diferentes ubicaciones, el lugar elegido fue la Feria Internacional del Campo de Madrid, la cual albergaría distintos pabellones de comunidades o del Estado. Puesto que el pabellón tuvo una gran acogida en Bruselas y su estructura contaba con una gran flexibilidad demostrada en la manera de adaptarse al abrupto terreno en el que se emplazó en la capital belga, se pensó que el cambio al Recinto de la Casa de Campo sería sencillo, pero el resultado final no consiguió mantener la misma esencia que en Bruselas, lo que hizo que fuera más plano y perdiese parte del efecto original del edificio, además de tener que adaptarse a los numerosos árboles que ramificaron el espacio interior lo que anuló la imagen de pilares infinitos creada en la construcción levantada en la exposición de Bruselas (Ruiz-Apilánez, 2018).

El traslado del pabellón tuvo lugar en 1959 y desde ese año comenzaría la aventura de una obra que, después del éxito conseguido a nivel internacional y de la acogida de manera definitiva por el régimen como propio (lo cual supuso un punto de inflexión y un cambio en la ruta de la futura arquitectura española), se vio sometido en años posteriores a la incertidumbre política en lo que respecta a su funcionalidad/utilidad y reconocimiento como hito arquitectónico histórico. Su éxito, a juzgar por el devenir posterior, fue tan breve como el sueño de una noche de verano.

A partir de los años sesenta los estudios sobre el pabellón de Corrales y Molezún comenzaron a aflorar, tanto en monografías ya históricas (Flores, 1961) como en los manuales (Benévolo, 1968). Las citas o investigaciones en publicaciones se fueron sucediendo a finales de los años 80 (Lampugnani, 1989) y a lo largo de los noventa, en las que se incluían imágenes del interior, planos y fotografías en color, así como comentarios de arquitectos de renombre que consideraban a esta construcción como una obra que dejó huella en la historia de la arquitectura española.

Pero su fama no murió en el siglo que le vio nacer, sino que en pleno siglo XXI nos seguimos encontrando con un abundante y continuo número de estudios e incluso congresos dedicados al tema de las Exposiciones Universales durante los años cincuenta, artículos de prensa y documentales que nos demuestran que, aunque nos encontremos a más de sesenta años de distancia, la Expo'58 y el Pabellón de España siguen siendo tema de interés y, por ende, de investigación. Nos han quedado para la posteridad desde documentales realizados en RTVE (2003) a uno de los arquitectos del pabellón, José Antonio Corrales ${ }^{17}$, pasando por monografías como Arquitecturas ausentes del siglo $X X$ (2004), en la que se presentaba al pabellón como una obra fundamental para comprender la arquitectura del siglo XX; la entrevista hecha en el semanal El Cultural del periódico El País a José Antonio Corrales en la que comentaba el éxito del pabellón y de lo que supuso para ellos como arquitectos creadores y para el momento político, social e históricoartístico en el que se hizo, o publicaciones monográficas en 2005 (Corrales et al., 2005), en revistas especializadas en 2009 (Fernández, 2009) y como uno de los casos de estudio en tesis doctorales (Jerez, 2012; Méndez-Navia, 2015).

A la par que se estaban realizando todas estas investigaciones y publicaciones, como fruto del interés por el que fuera uno de los edificios emblemáticos del pasado siglo, se estaba dilucidando acerca de un nuevo traslado desde la Casa de Campo en Madrid (lugar en el que permaneció abierto hasta 1975). Las opciones que se barajaban eran desde ubicarlo en el Paseo Imperial (1991), hasta llevar a cabo un plan de rehabilitación y emplazamiento en el Campo de las Naciones (2001) o convertirlo en la nueva jefatura de bomberos (2014). Mientras tanto la maleza ha seguido acampando por doquier junto con los gatunos inquilinos. Así se llega al año 2019, en el que el pabellón continúa totalmente descuidado y prácticamente en estado de ruina, producto de la dejadez de las administraciones a las que pertenece y a la falta de interés por mantenerlo al no ser Bien de Interés Cultural (BIC), porque esta es la cruda realidad: nunca ha llegado a reconocerse como tal a pesar de la destacada trayectoria técnico-histórico-artística que posee, tal y como hemos puesto de manifiesto (Fig. 3) ${ }^{18}$.

\footnotetext{
${ }^{17}$ RTVE, "Elogio de la luz- José Antonio Corrales, voluntad indomable", 27-III-2003.

http://www.rtve.es/alacarta/videos/elogio-de-la-luz/elogioluz-jose-antonio-corrales-voluntad-indomable/15510 (fecha de consulta: 10-XI-2019).

${ }^{18}$ El pabellón pertenece a “Casa de Campo- Recintos Feriales” recinto que sí que está catalogado como BIC desde 2010, hecho que ni aun así animó a rehabilitar la joya proyectada por Corrales y Molezún.
} 


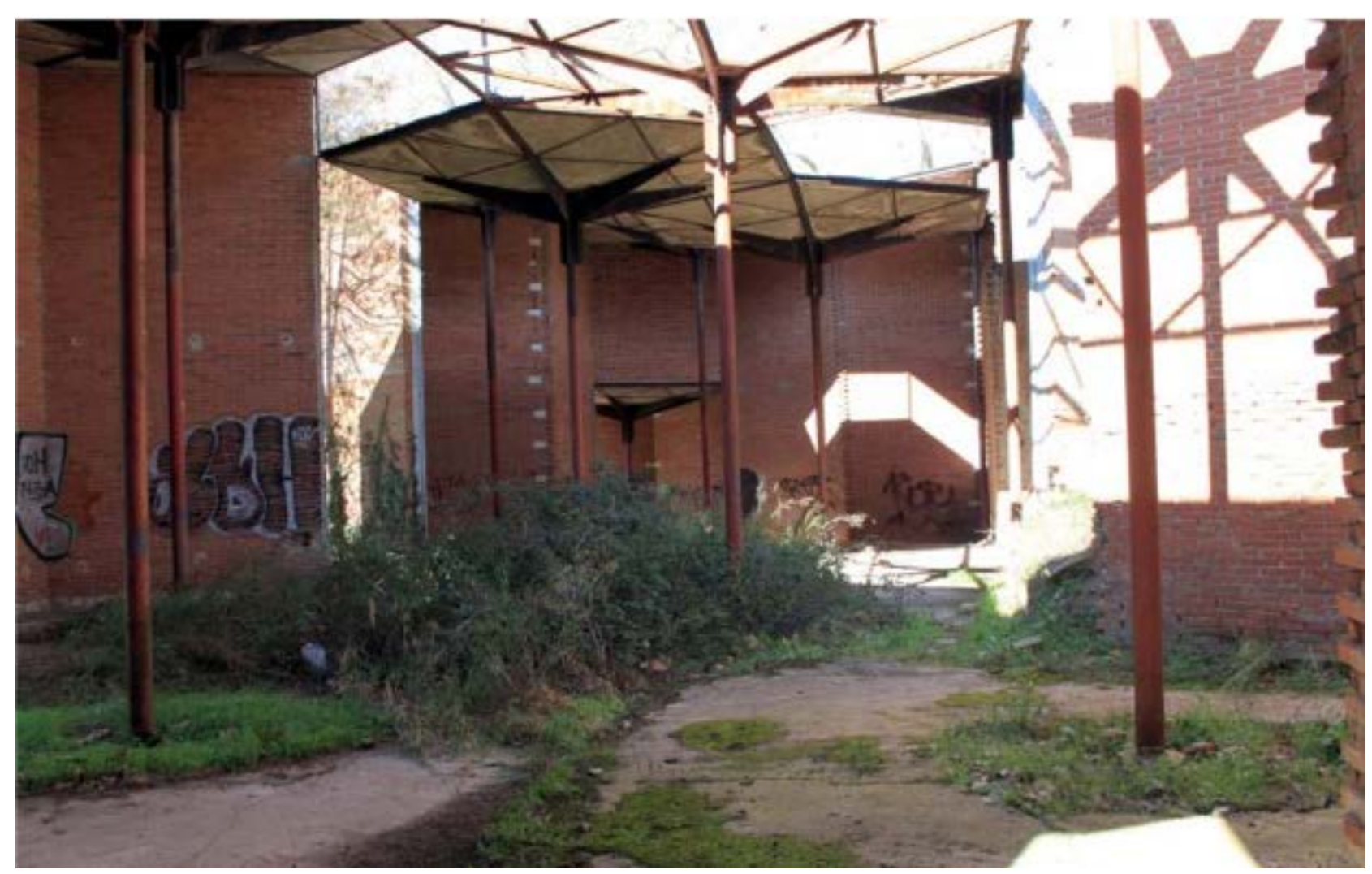

Fuente: Ruiz-Apilánez, I. (2018)

Fig. 3 Estado del pabellón en la actualidad

Hace unos meses el diario El País publicó un artículo que auguraba ilusionantes noticias para la recuperación del pabellón español que nos representó de manera tan destacada en Bruselas ${ }^{19}$. El titular "La resurrección del Pabellón de los hexágonos, un edificio que es como un mecano", nos abre una puerta a la esperanza de que esta construcción vuelva por fin a la vida, se le otorgue el reconocimiento que merece y sea, de verdad, una oportunidad para demostrar la importancia de la conservación de la arquitectura contemporánea como parte de nuestro patrimonio histórico. Un sueño que ojalá se haga realidad.

\section{Referencias}

Baldellou, M. A., y Capitel, A. (1996). Arquitectura del siglo XX. Summa Artis, Historia General del Arte XL, Tomo 40. Madrid: Espasa Calpe.

Benévolo, L. (1963). Historia de la arquitectura moderna. Madrid: Taurus.

Cánovas, A., y Corrales, J. A. (2005). Pabellón de Bruselas '58: Corrales y Molezún. Madrid: Departamento de proyectos ETSAM, Universidad Politécnica de Madrid.

Capitel, A. et al. (2000). Arquitectura del siglo XX: España. Sevilla: Tanais.

Cejador, M. Á. (2019). La museografía del pabellón español de la Exposición Internacional de Bruselas de 1958: un ejemplo de la tensión entre modernidad y tradición en la España franquista. En J. A. Gracia et al. (Coords.), III Jornadas de Investigadores Predoctorales. La Historia del Arte desde Aragón. Universidad de Zaragoza.

Cortés, J. A. (2000). Internacionalismo y referencias vernáculas en los años cincuenta. En A. Capitel et al. (Eds.) Arquitectura del siglo XX: España (pp. 140-148). Sevilla: Tanais.

19 “La resurrección del Pabellón de los hexágonos, un edificio que es como un mecano”, El País (Madrid, 16-III-2019). 
Doménech, L. (1968). Arquitectura española contemporánea. Barcelona: Blume.

Fernández-Galiano, L. (2009). España y su fantasma. Representación e identidad en las exposiciones universales, máximas atracciones de la EXPO '58 de Bruselas. Arquitectura Viva 129, 24.

Flores, C. (1961). Arquitectura española contemporánea. Madrid: Aguilar.

Hernández, A. (2013). Dentro/fuera. Contradicciones y paradojas de la arquitectura bajo el franquismo a través de las exposiciones y pabellones de arquitectura efímera. En A. Martínez Herranz (Coord.), La España de Viridiana (pp. 107-127). Zaragoza: Prensas de la Universidad de Zaragoza.

Jerez, E. (2012). El legado de lo efímero. 1937-2010, la arquitectura proyectada y construida de los pabellones de España en las Exposiciones Universales. Tesis doctoral. Valladolid: Escuela Técnica Superior de Arquitectura de Valladolid.

Lampugnani, V. M. (1989). Enciclopedia GG de la arquitectura del siglo XX. Barcelona: Gustavo Gili.

Méndez-Navia, V. (2015). Lo permanente en lo efímero. Pabellones de Exposiciones universales, hitos de la arquitectura de la segunda posguerra. Tesis doctoral. Madrid: ETSAM, Universidad Politécnica de Madrid.

Ruiz, G. (2001). El Moderno en España, Arquitectura 1948-2000. Madrid: Tanais.

Ruiz-Apilánez, I. (2018). Estado actual, patologías y rehabilitación del Pabellón de los Hexágonos de la Casa de Campo. Trabajo Fin de Grado. Madrid : ETSAM, Universidad Politécnica de Madrid. 